\title{
Vector of Trophic Resource Partitioning in the Variability of Individuals of the Generalized form of the Large African Barbs of the Barbus (= Labeobarbus) Intermedius Complex, Ethiopia, Tana, Langano and Awasa Lakes
}

\author{
A. N. Mironovsky ${ }^{a, b, *}$ \\ ${ }^{a}$ Severtsov Institute of Ecology and Evolution, Russian Academy of Sciences, Moscow, 119071 Russia \\ ${ }^{b}$ Papanin Institute for Biology of Inland Waters, Russian Academy of Sciences, Borok, Yaroslavl oblast, 152743 Russia \\ *e-mail: adissa@mail.ru
}

Received June 11, 2020; revised November 17, 2020; accepted November 26, 2020

\begin{abstract}
Analysis of the diversification of barbs of the generalized form of the Barbus (= Labeobarbus) intermedius complex in the monomorphic populations of Langano and Awasa lakes and in the polymorphic population of Lake Tana makes it possible to reveal parameters of the variability that is directed to trophic resource partitioning. The great similarity of the parameters revealed in the three studied water bodies shows that in monomorphic populations the structure of variability directed to trophic resource partitioning is identical to that in the polymorphic population. The concept of "vector of trophic resource partitioning" is introduced. In the polymorphic population, this vector makes the main contribution to the diversification of individuals, while its importance is secondary in monomorphic populations. It is concluded that the different evolutionary potential of polymorphic and monomorphic populations is determined by the specific weight of diversification caused by the vector of trophic resource partitioning. The original method of data analysis used in the study may be promising for studying similar situations in other systematic groups.
\end{abstract}

Keywords: large African barbs, Barbus (=Labeobarbus) intermedius complex, generalized form, variability vectors, sympatric speciation

DOI: $10.1134 / \mathrm{S} 003294522104010 \mathrm{X}$

\section{INTRODUCTION}

Individuals with no obvious signs of food specialization are considered to be generalized in the system of phenetic diversity of large African barbs of the Barbus intermedius complex (sensu Banister, 1973) (Nagelkerke et al., 1994; Mina et al., 1996a, 1996b; Levin, 2003; Golubtsov, 2010; Levin et al., 2019). Such individuals are found in every body of water where representatives of the complex live, while almost all forms specialized in terms of feeding are known only from those localities where they were described. The presence in any population of the range gives grounds to consider the generalized individuals as kin (or identical) to individuals of the ancestral form, which, in the course of its diversification, gave rise to the entire diversity of the $B$. intermedius complex. This hypothesis is supported by the results of numerous studies (Nagelkerke et al., 1994; Mina et al., 1996a, 1996b; Sibbing et al., 1998; Sibbing and Nagelkerke, 2000; Levin et al., 2019), in particular, the analysis of the variability of morphological characters of generalized individuals of different populations in comparison with the variability of individuals of sympatric morphotypes in Tana Lake and allopatric species of large African barbs (Mironovsky, 2020). As it turned out, the vectors of diversification of the generalized form inhabiting lake Tana, are very similar both to peer-to-peer vectors of the Tana's morphotypes and to the corresponding vectors of allopatric species of barbs. The high degree of this similarity suggests that the diversification of individuals of the generalized form in lake Tana, diversification of the Tana's morphotypes and diversification of allopatric species are successive stages of one process, and the diversification of morphotypes and species proceeds in the directions set by the diversification of individuals of a generalized form. This is strong evidence in favor of the hypothesis that a generalized form is kin to the ancestral one. At the same time, a comparison of peer-topeer diversification vectors of monomorphic populations of generalized individuals from Lakes Langano and Awasa revealed their similarity and significant differences from the corresponding vectors of diversifica- 


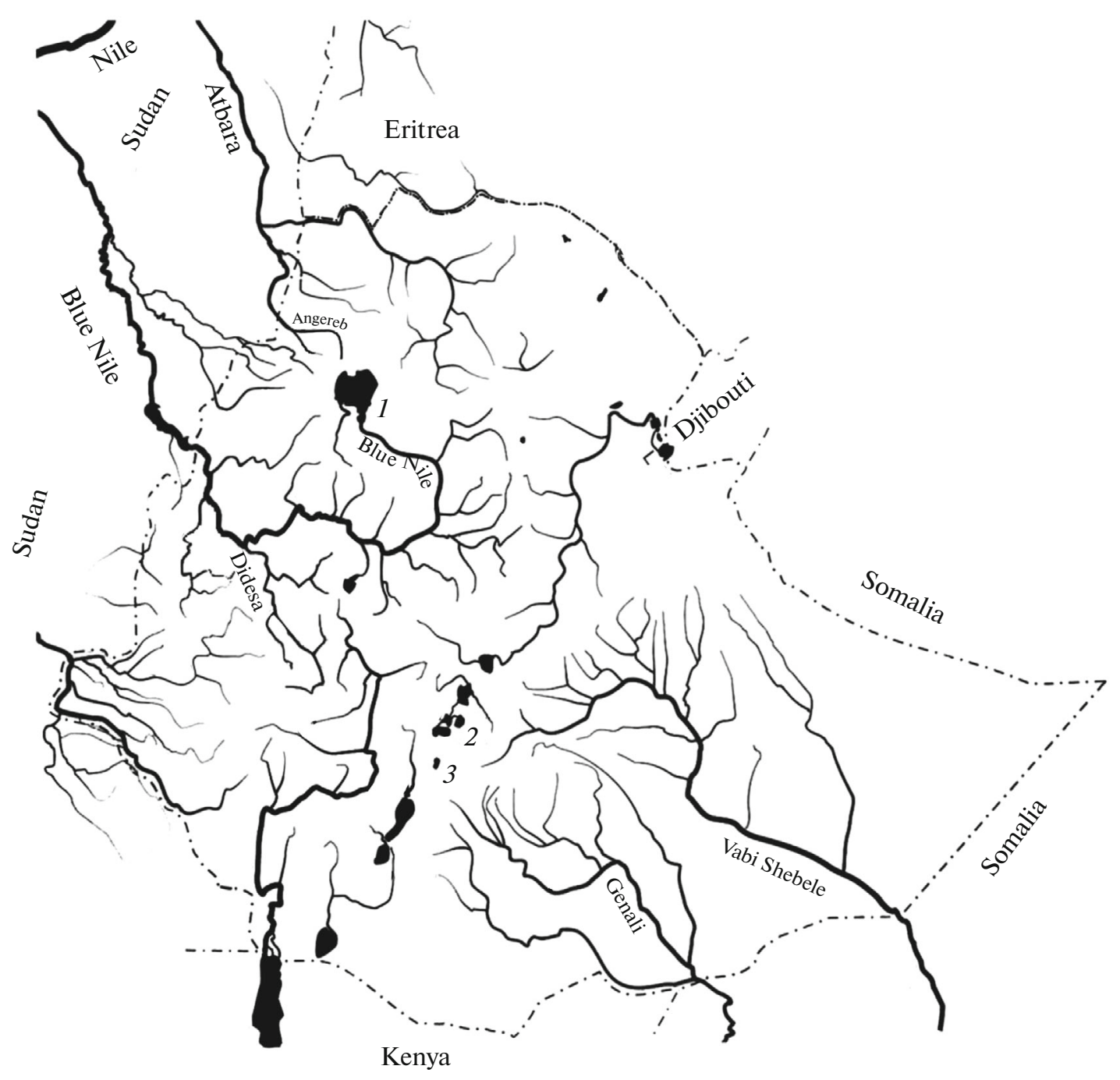

Fig. 1. Schematic map of the study region. Lakes: 1- Tana, 2-Langano, 3-Awasa.

tion of generalized individuals in Lake Tana. This suggests that the of the generalized form of barbs may proceed in different directions in different localities.

The goal of this study is to find an answer to the question: what is that difference in the diversification of generalized individuals in the polymorphic population of Lake Tana and in the monomorphic populations of Lakes Awasa and Langano, which determines the differences in their evolutionary potential?

\section{MATERIALS AND METHODS}

Materials for research were sampled in three Ethiopian lakes: Tana in 1992-2010, Awasa in 1997-2016 and Langano in 2007-2011 (Fig. 1). Fish were caught with gill and cast nets, taken from the catches of local fishermen. Lake Tana is home to a polymorphic population of large African barb; generalized form (GF) of this population is described as morphotype intermedius ${ }^{1}$
(Nagelkerke et al., 1994; Mina et al., 2016). In comparison with the variety of barbs' forms in Lake Tana populations of lakes Awasa and Langano may be considered near to monomorphic. A poorly expressed polymorphism in the proportions of the skull, found in fish from these lakes, suggests only a barely outlined divergence into two groups-euryphagous and piscivorous-and is not associated with any differences in external characters (Mina et al., 2016). The size of the GF sample from Lake Tana was 119 individuals of standard length $(S L)$ 17.0-28.7 cm, Lake Awasa-49 specimens $S L$ 17.9-28.3 cm, Langano-73 specimens $S L 12.4-34.7 \mathrm{~cm}$.

\footnotetext{
${ }^{1}$ Latin "intermedius", as well as the definition "generalized" indicates the generality of the habitus of GF individuals-intermediate, or averaged, between other Tana morphotypes. Nagelkerke et al. (1994. P. 3) indicate the absence of "extreme characters" as the main diagnostic feature of the morphotype intermedius, by "extreme" meaning the diagnostic features of specialized lake morphotypes.
} 

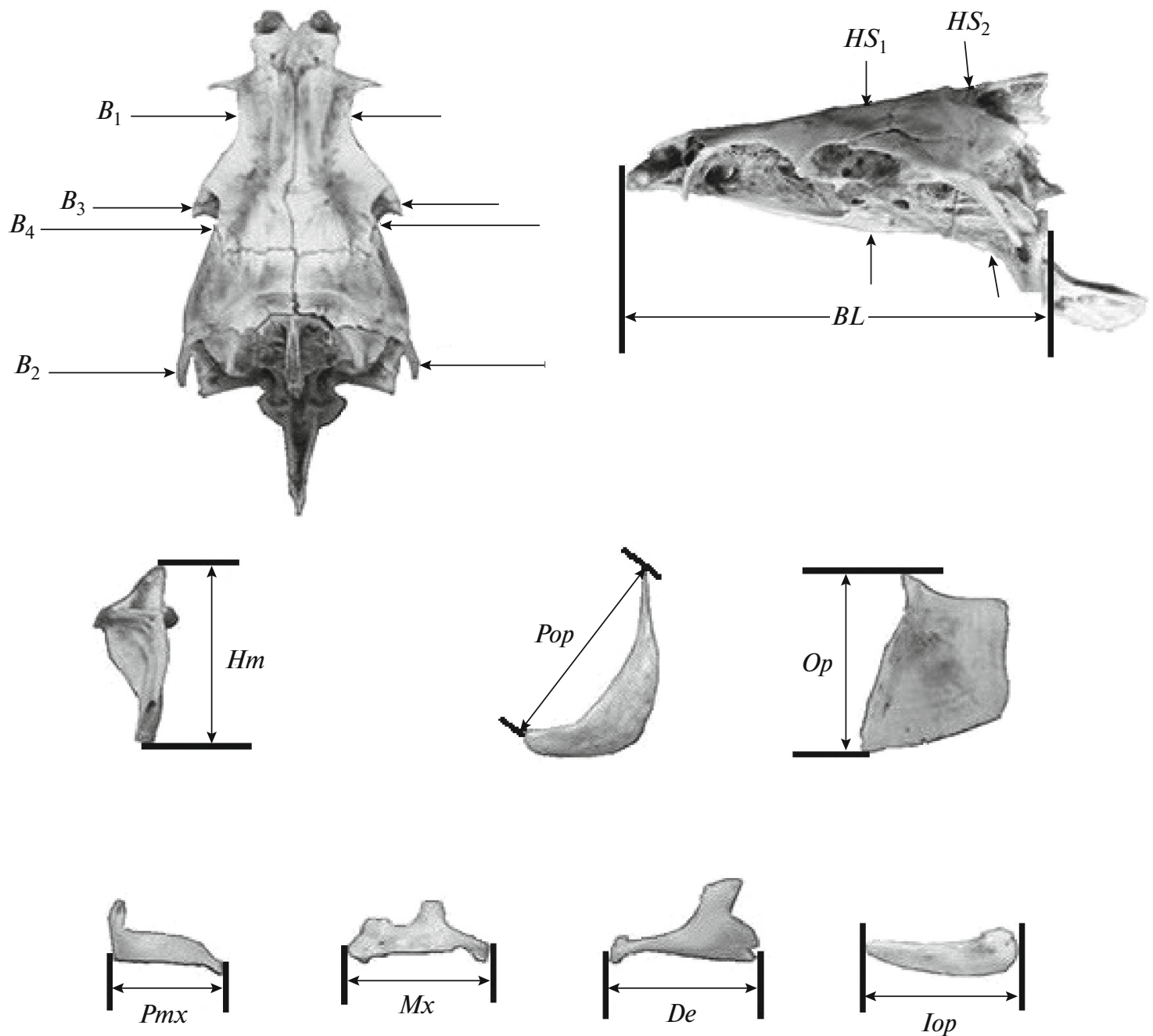

Fig. 2. Scheme of skull measurements of fish of the Barbus intermedius complex: $B L$-basal length of neurocranium; $B_{1}, B_{2}, B_{3}-$ the distance between the outer edges of frontalia, pterotica and sphenotica, respectively; $B_{4}$ - the neurocranium width at the level of the frontale and pteroticum junction; $H S_{1}$ and $H S_{2}$-neurocranium height at the level of bend of parasphenoideum and the posterior edge of parasphenoideum, respectively; $\mathrm{Hm}$ - the height of hyomandibulare; Pop -the length of the praeoperculum; $O p$-the height of the anterior part of the operculum; Pmx, Mx, De, and Iop are the lengths of praemaxillare, maxillare, dentale, and interoperculum, respectively.

For each individual, 14 skull measurements were made (Fig. 2). As the study of the variability of large African barbs has shown, this set of characters, provides high resolution and good reproducibility of measurement results both by a single or multiple operators, making it possible to assess the phenetic relationships of most morphotypes fairly confidently (Mina et al., 1993, 1996a, 1996b, 1998; Mironovsky, 2006).

Statistical data processing was performed using the NTSYS 2.02k (Rohlf, 1998) and Statistics 6 software packages. Following indices were used-the ratio of the absolute values of measurements to the basal length of the cranium $(B L)$. Further, when mentioning a particular character, we mean its index, and not the measurement itself. The index values were con- verted to natural logarithms to normalize the distributions.

In principal component analysis (PCA), the eigenvectors were calculated using the correlation matrix; the length of the vector was set to 1 . In contrast to the works in which the PCA is used to reduce the number of variables with the subsequent analysis of the distribution of the studied points (fish) in the two- or threedimensional space of the first PCs, this study is based on the analysis of the similarity and difference between the eigenvectors (EV) of the correlation matrices characterizing the main directions of variance of objects of the sets under consideration (Andreev and Reshetnikov, 1978; Andreev, 1980; Dgebuadze et al., 2008; Mironovsky, 2020). The main directions of variance are considered as the main 
Table 1. Eigenvectors (EV1, EV2): eigenvalues and loadings of the considered characters in populations of generalized barbs of the Barbus intermedius complex of lakes Tana, Awasa and Langano

\begin{tabular}{c|c|c|c|c|c|c}
\hline \multirow{2}{*}{ Character } & \multicolumn{2}{|c|}{ Tana } & \multicolumn{3}{c}{ Awasa } & \multicolumn{2}{c}{ Langano } \\
\cline { 2 - 7 } & EV1 & EV2 & EV1 & EV2 & EV1 & EV2 \\
\hline$B_{3}$ & 0.300 & 0.113 & 0.255 & 0.377 & 0.282 & 0.292 \\
$B_{2}$ & 0.203 & 0.292 & 0.257 & 0.308 & 0.240 & 0.163 \\
$B_{1}$ & 0.320 & 0.213 & 0.250 & 0.323 & 0.349 & 0.280 \\
$B_{4}$ & 0.309 & 0.144 & 0.369 & 0.224 & 0.160 & 0.422 \\
$H S_{1}$ & 0.332 & -0.063 & -0.094 & 0.167 & -0.126 & 0.347 \\
$H S_{2}$ & 0.340 & 0.107 & 0.179 & 0.321 & 0.049 & 0.495 \\
$H m$ & 0.283 & 0.306 & 0.153 & 0.305 & 0.004 & 0.354 \\
$P m x$ & -0.369 & 0.317 & 0.344 & -0.276 & 0.392 & -0.211 \\
$P o p$ & 0.011 & 0.422 & 0.231 & -0.068 & 0.266 & 0.055 \\
$O p$ & 0.086 & 0.429 & 0.390 & -0.071 & 0.237 & -0.042 \\
$I o p$ & -0.246 & 0.264 & 0.288 & -0.335 & 0.345 & -0.188 \\
$M x$ & -0.271 & 0.385 & 0.322 & -0.338 & 0.437 & -0.155 \\
$D e$ & -0.296 & 0.213 & 0.308 & -0.270 & 0.326 & -0.178 \\
Eigenvalues & 3.700 & 2.580 & 4.490 & 2.370 & 4.150 & 2.160 \\
Variance explained \% & 28.5 & 19.9 & 34.5 & 18.3 & 31.9 & 16.6 \\
\hline
\end{tabular}

$B_{1}, B_{2}, B_{3}$-distance between outer edges of frontalia, pterotica and sphenotica, respectively; $B_{4}$-width of neurocranium at the level of the junction of the frontale and pteroticum; $H S_{1}, H S_{2}$-neurocranium height at the bend level of parasphenoideum and the posterior edge of parasphenoideum, $\mathrm{Hm}$-height of hyomandibulare; Pmx, Pop-length of praemaxillare and praeoperculum, $O p-$ anterior operculum height; Iop, $M x$, De-length of interoperculum, maxillare and dentale, respectively.

directions of variability (diversification, divergence) of barbs in the studied water bodies. To assess the similarity of character loadings on eigenvectors, the Spearman rank correlation coefficient $\left(r_{\mathrm{S}}\right)$ was used, the significance of $r_{\mathrm{S}}$ was assessed using the Statistica 6 software package. As shown in the previous study (Mironovsky, 2020), the ordered (stable, directed, consistent, constructive) variability ("signal"), which determines the divergence of morphotypes and species of large African barbs, is concentrated in the first two eigenvectors, EV1 and EV2; further (in EV3, EV4, EV5 ...) "noise" prevails, i.e. the variability is stochastic, random (Kaiser, 1960). Therefore, the analysis in this study is limited to EV1 and EV2.

\section{RESULTS AND DISCUSSION}

To compare the variance of barbs of the studied populations, we construct the distribution of points that correspond to the factor loadings of the variables under consideration on the EV of the compared samples in a rectangular coordinate system. In the hypothetical case, when the directions of variability in a pair of matched samples are identical (i.e. the diversification processes coincide completely), the points corresponding to the character loadings will lie on a straight line located at an angle of $45^{\circ}$ to the coordinate axes, the correlation between the loading values will be equal to 1 . The points on such a graph are located the farther from the origin of coordinates, the greater the loading a given character has in a given direction of variability. At the origin, there will be points corresponding to the variables with the lowest loadings in the given direction of variability. The graphs reflecting the results of a peer-to-peer comparison of the first two EV of the variance of individuals in each of the three analyzed sets of barbs (table) are given in Fig. 3.

The sign opposition ("-" and "+") of $H S 1$ and 12 other parameters in the distribution of the loadings of characters on EV1 is common for the monomorphic populations of lakes Awasa and Langano: the loadings of $H S_{1}$, almost coinciding in value in both samples, are located in the third quarter of the coordinate plane, while the loadings of the other 12 parameters are in the first one (Fig. 3a). There is no opposition " $H S_{1}$ versus all" in the population from Lake Tana but another opposition of signs is present: the loadings of the jaw morphology parameters (De, Pmx, and $M x)$ and one of the operculum parameters (Iop) are located in the third quarter of the coordinate plane ("-"), and the loadings of other nine characters-in the first ("+") (Figs. 3b, 3c). Two parameters of the operculum (Pop and $O p$ ) are located at the origin of coordinates, from which it follows that their weight in the variance according to EV1 is relatively small and the main con- 
(a)

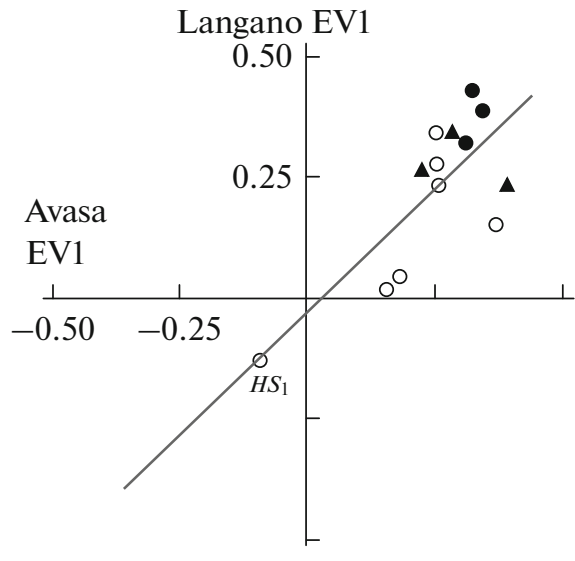

(c)

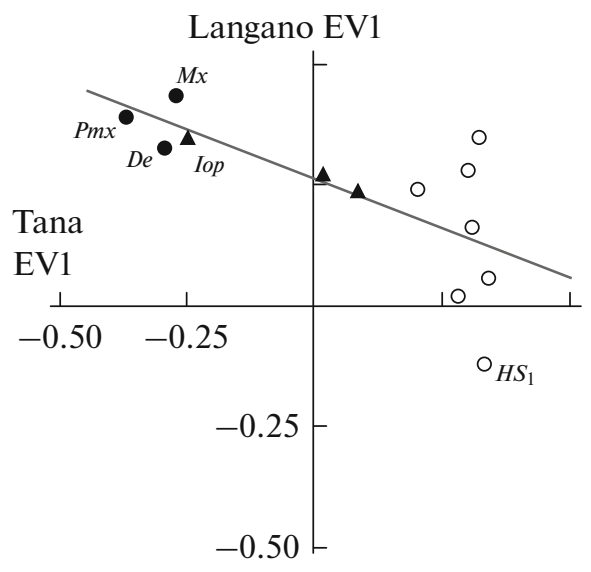

(e)

Avasa EV2

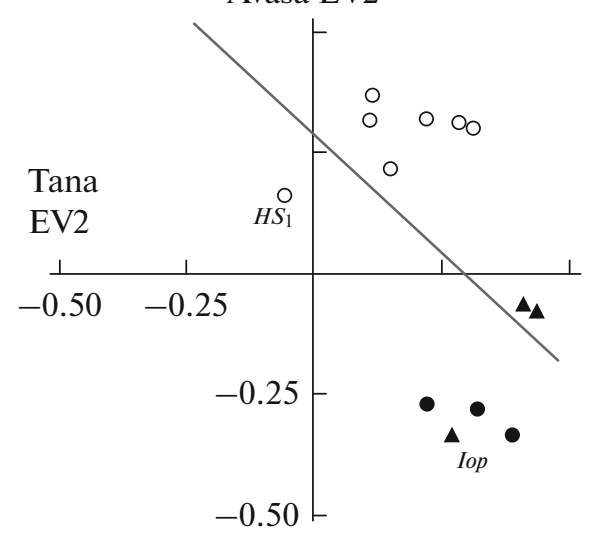

(b)

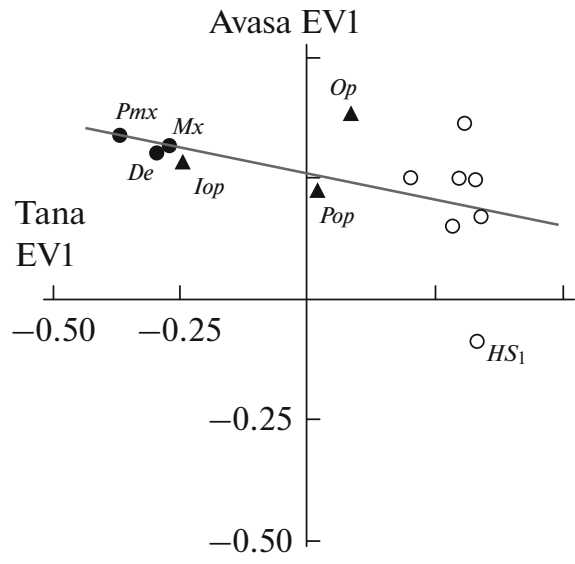

(d)

\section{Langano EV2}

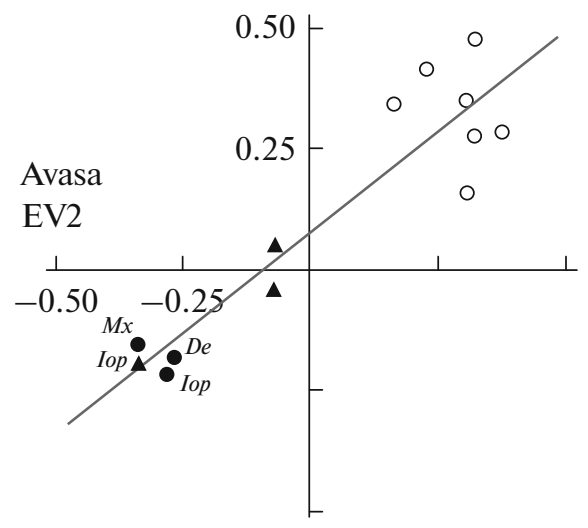

(f)

Langano EV2

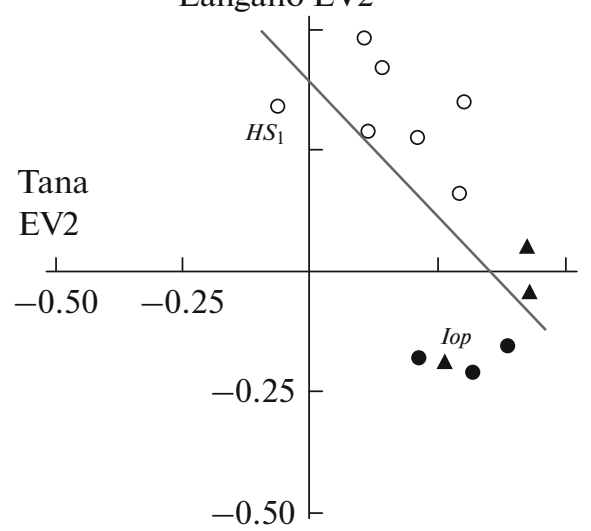

Fig. 3. Comparison of peer-to-peer eigenvectors-EV1 $(a-c)$ and EV2 $(d-f)-$ variances of individuals of the generalized form (GF) of the Barbus intermedius complex from lakes Tana, Awasa, and Langano: a-Awasa-Langano, $r_{\mathrm{s}}=0.472, p=0.103 ; \mathrm{b}-$ Tana-Awasa, $r_{\mathrm{s}}=-0.566, p=0.043 ; \mathrm{c}-$ Tana-Langano, $r_{\mathrm{s}}=-0.664, p=0.013 ; \mathrm{d}-$ Awasa-Langano, $r_{\mathrm{s}}=0.758, p=0.003 ; \mathrm{e}-$ Tana-Awasa, $r_{\mathrm{s}}=-0.505, p=0.078 ; \mathrm{f}-$ Tana-Langano, $r_{\mathrm{s}}=-0.566, p=0.044$. Loadings of parameters: $(\bullet)-$ jaw arch: Pmx,

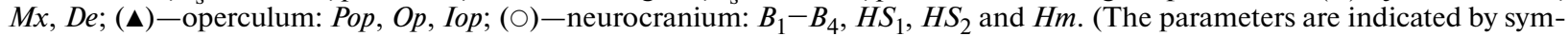
bols and inscriptions only to the extent necessary for understanding the presentation in order not to clutter the figures). 
tribution to the variability in this direction in the population of Lake Tana is introduced by the opposition of the groups De, Pmx, Mx, Iop ("-") and $B_{1}-B_{4}, H S_{1}$, $H S, H m$ ("+"). The difference in the oppositions of signs and the composition of opposing groups makes the distribution of parameter loadings on EV1 in polymorphic and monomorphic populations dissimilar, and the significance of the correlation between them confirms the pattern of this dissimilarity.

The similarity of the variance of generalized barbs in the populations of lakes Awasa and Langano according to EV2 is evidenced by a high statistically significant correlation between the corresponding EV2 (Fig. 3d). The first thing that attracts attention when analyzing the corresponding distribution is the distinct opposition of two groups of vector loadings, which are approximately the same in absolute value, but differ in sign. The first group is $D e, P m x, M x$ and Iop ("-"), the second is $B_{1}-B_{4}, H S_{1}, H S_{2}$ and $H m$ ("+"). High values of loadings indicate that the main contribution to the variance of individuals, determined by EV2, is made by these opposing groups. Two characters of the operculum ( $P o p$ and $O p$ ) are located at the origin of coordinates, it's not possible to confidently judge their belonging to one of the groups, and their loadings on vectors are close to 0 , i.e., their contribution to the variance of objects of the studied populations in this direction of variability is rather small.

As we can see, the distribution of characters' loadings on EV2 in monomorphic populations (Fig. 3d) clearly resembles the distribution of characters' loadings on EV1 in the polymorphic population of Lake Tana (Figs. 3b, 3c). Whereas in the distribution of the loadings of characters on EV2 in the sample from Lake Tana (Figs. 3e, 3f), we see the opposition between $H S_{1}$ and 12 other parameters, which was observed earlier (Fig. 3a). The analysis of the data in Fig. 3 gives obvious reasons to believe that the direction of diversification of individuals, which corresponds to EV1 (Fig. 3a) in monomorphic populations, in the polymorphic population corresponds to EV2 (Figs. 3e, 3f). And vice versa: the direction of diversification of individuals, corresponding to EV1 in the polymorphic population (Figs. 3b, 3c), corresponds to EV2 in monomorphic populations (Fig. 3d).

This assumption is illustrated more clearly in Fig. 4, where the relations of monomorphic and polymorphic populations are analyzed by comparing vectors of not the same but different ranks. Comparing the EV1 of the polymorphic population of Lake Tana with EV2 of each of the monomorphic populations (Figs. 4a, 4b), we see that the loadings of characters are very similar both to each other and to the loadings of characters in comparing the EV2 of two monomorphic populations (Fig. 3d). The correlation between EV in the three indicated comparisons is high and statistically significant, which confirms the regularity of their similarity. The graphs reflecting the distribution of loadings in comparison of the EV2 of the polymorphic population with the EV1 of monomorphic populations are also similar to each other (Figs. 4c, 4d), as well as to the loadings distribution graph in the comparison of the EV1 of two monomorphic populations (Fig. 3a). In these three comparisons, the correlation between EV is statistically insignificant, which does not allow us to consider the similarity of vectors as an unquestionable regularity. At the same time, the striking similarity of distribution patterns in the three indicated comparisons may hardly be regarded as a matter of blind chance. On each of the three graphs (Figs. 3a, 4c, 4d), the characters are distributed only in the first and third coordinate planes, 12 out of 13 considered parameters are concentrated in the first quarter of coordinates, in the third quarter we invariably see the $H S_{1}$ symbol (neurocranium height at the level of parasphenoid bend). Obviously, the separation of 13 characters in a ratio of $12: 1$ so that in three independent observations (in the populations of three lakes) the parameter opposing the others in the sign of the loading on the vector turns out to be the same parameter $H S_{1}$, indicates, if not a pattern, then clearly a pronounced trend that certainly deserves attention and further study.

The structure of character distributions in Figs. 3d, $4 \mathrm{a}$, and $4 \mathrm{~b}$ almost coincides with the structure of correlation pleiades revealed when assessing the correlations of the same 13 characters in the process of B. intermedius complex diversification (Mironovsky, 2020). The group of De, Pmx, Mx, Iop and the group of $B_{1}-B_{4}, H S_{1}, H S_{2}, H m$ are spaced along the edges of the distributions; the absolute value of the loading of the characters of the two specified groups on the vectors is approximately equal. The pair of $P o p$ and $O p$ is located at almost equal distance from these groups at the origin of coordinates. Similarly, on the dendrograms of correlations that revealed the pleiades, one cluster consisted of De, Pmx, Mx , and Iop, and the second $-B_{1}-B_{4}, H S_{1}, H S_{2}, H m$ (Mironovsky, 2020). The characters $P o p$ and $O p$, formally entering the cluster with $B_{1}-B_{4}, H S_{1}, H S_{2}, H m$, occupy an outermost position in it, and the analysis of the correlation matrices used for the dendrograms shows that this pair of characters is approximately equidistant from both groups and falling into one of the clusters was determined by the second decimal places. It was concluded that the opposition of the identified pleiades, expressed in a significant negative correlation between them, is inherent in the diversification of individuals in the process of trophic resource partitioning (Mironovsky, 2020). A similar opposition in the sign of loadings on the EV ("+" or "-"), a high similarity of the distribution pattern and high statistically significant correlations in Figs. 3d, 4a, and 4b make it possible to consider the compared EVs as different realizations of the vector of trophic resource partitioning in different populations of generalized individuals. It is the different realizations of the same vector, common for indi- 
(a)

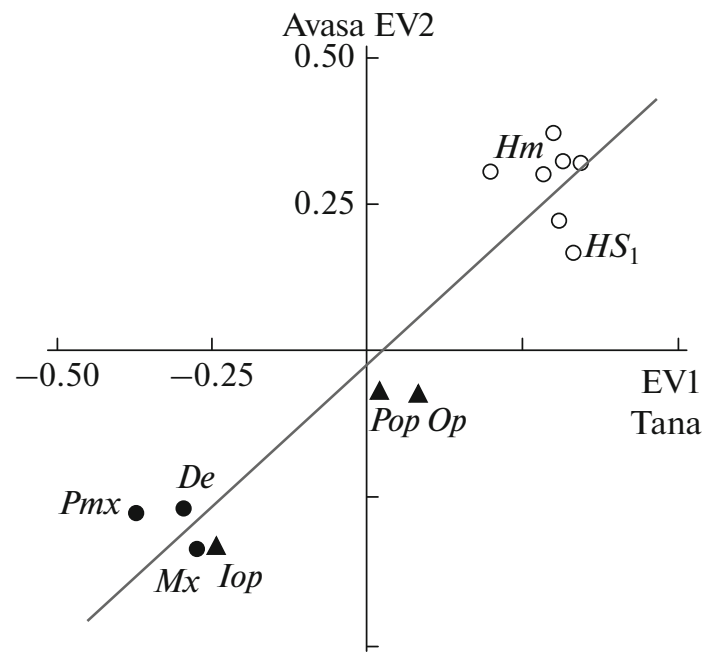

(c)

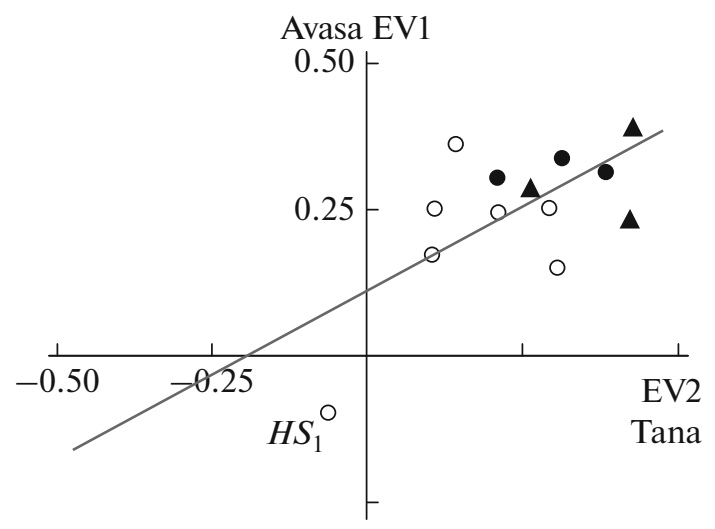

(b)

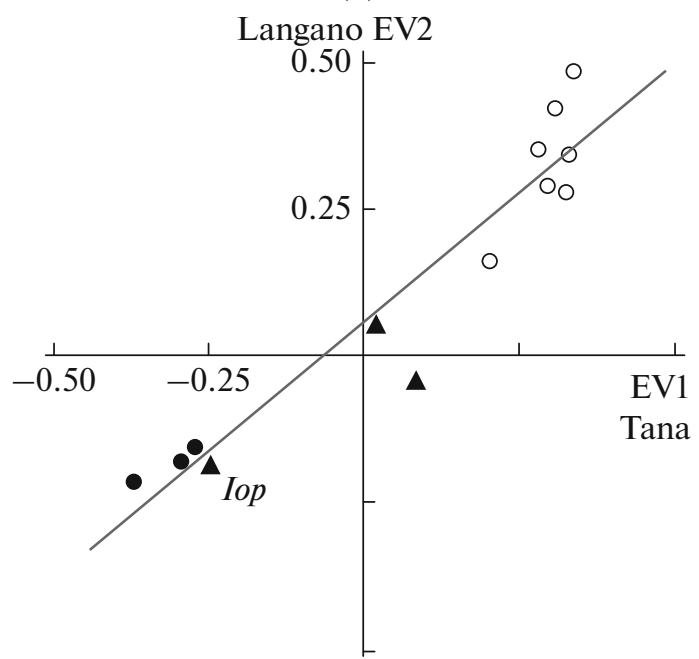

(d)

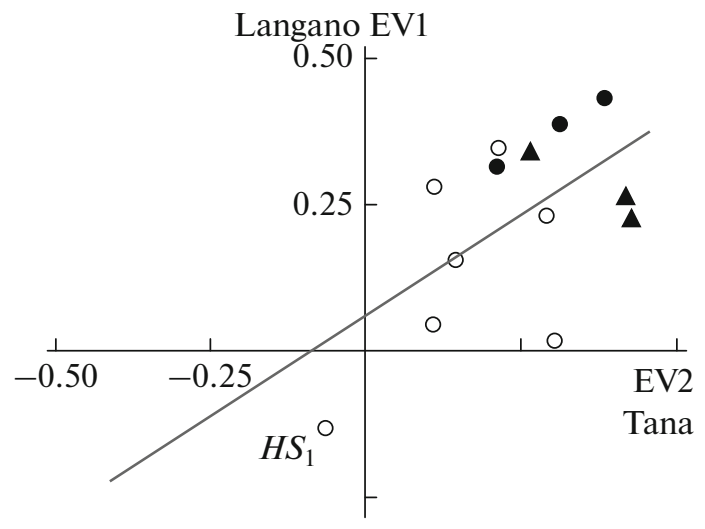

Fig. 4. Comparison of different-rank eigenvectors (EV1-EV2) of the variance of GF individuals of the Barbus intermedius complex: a-Tana EV1- Awasa EV2, $r_{\mathrm{s}}=0.786, p<0.001$; $\mathrm{b}$-Tana EV1- Langano EV2, $r_{\mathrm{s}}=0.907, p<0.001$; - Tana EV2- Awasa $\mathrm{EV} 1, r_{\mathrm{s}}=0.428, p=0.143$; d-Tana EV2-Langano EV1, $r_{\mathrm{s}}=0.379, p=0.201$; see notation in fig. 3 .

viduals of the three studied populations, but not of different vectors in the polymorphic and in the monomorphic populations. This assumption is also supported by the fact that when comparing the EV of polymorphic and monomorphic populations (Figs. $4 \mathrm{a}, 4 \mathrm{~b}), r_{\mathrm{s}}$ is higher than when comparing the EV of monomorphic populations with each other (Fig. 3d).

The similarity of EV of different ranks revealed in this study allows developing one of the provisions of the previous study on the variability of the studied fish group (Mironovsky, 2020). The results of peer-to-peer comparison of EV1 and EV2 were interpreted then as an evidence of the existence of four main vectors of diversification of large African barbs. As it seemed then, two of them determine the diversification of generalized barb in Lake Tana. Another two are the vectors of diversification in monomorphic barb populations in Lakes Awasa and Langano. The results of present study suggest that there are not four, but just two main directions of variability. The first is deter- mined by the clearly expressed opposition of just two groups of characters; the basis of one of the groups is the parameters of the mandibular arch (Figs. 3d, 4a, $4 b$ ). This presupposes a direct relation between the diversification and the trophic resource partitioning (hereinafter, this direction of variability will be designated as the trp-vector, i.e., the vector of trophic resource partitioning). The meaning of the opposition " $H S_{1}$ versus 12 other characters" is not obvious, and the factors that determine the second direction of variability are also not obvious (therefore, hereinafter, the second diversification vector will be called the $\boldsymbol{x}$-vector). Referring to Figs. 3a, 4c and 4d, it may be seen that the loadings of the parameters of the mandibular arch are also high here, giving grounds to believe that the feeding factor is significant in the second direction of variability as well, although here this factor is clearly not the only one and, apparently, not the main one.

In the case of two (rather than four) main vectors of variability, the difference in diversification of general- 
ized barbs in different populations is determined by which of them in the given one corresponds to EV1 and which corresponds to EV2. In the population of Lake Tana the position of EV1 is occupied by the trpvector (Figs. 4a, 4b), while position of EV2 is the position of the $\boldsymbol{x}$-vector (Figs. 4c, 4d). The opposite is true for the populations of Lakes Langano and Awasa: the position of EV1 is occupied by the $x$-vector there (Figs. 3a, 4c, 4d), and EV2 is the position of the trp-vector (Figs. 3d, 4a, 4b). Thus, the eigenvector of any of the two considered ranks (EV1 and EV2) in some cases may correspond to diversification directed to trophic resource partitioning (trp-vector), in other cases diversification under the influence of the $\boldsymbol{x}$-vector of an unclear direction at this stage of research. Referring to the table, we see that in Lake Tana, where the trpvector occupies the position of EV1, it accounts for $28.5 \%$ of the total variance; in lakes Awasa and Langano, where the position of the trp-vector is EV2, the proportion contribution of variability determined by it is 18.3 and $16.6 \%$, respectively. As the present study shows, it is this difference in the proportions of variability directed to trophic resource partitioning that apparently determines the difference in the intensity of trophic radiation of generalized individuals in these lakes.

It is interesting that in the figures, where vectors of the same pair of populations are compared-Langano and Awasa (Figs. 3a, 3d), Tana and Awasa (Figs. 4a, 4c), Tana and Langano (Figs. 4b, 4d), correlations between pairs of trp-vectors (Figs. 3d, 4a, 4b) are high and statistically significant, while the correlations between pairs of $\boldsymbol{x}$-vectors (Figs. 3a, 4c, 4d) are insignificant. This suggests that, in comparison of populations, the similarity of diversification of individuals in the process of trophic resource partitioning is higher than the similarity of their diversification by the sum of factors of an unobvious orientation (or vice versa: interpopulation differences in diversification in the process of trophic resource partitioning are lower than the interpopulation differences in diversification by factors of an unobvious orientation). In other words, the diversification of individuals with respect to the division of food resources in polymorphic and monomorphic populations of generalized barbs goes in a similar way, and the evolutionary potential of a population is determined by the rank (EV1 or EV2) of the trp-vector that determines this process, i.e. by share of variability directed to trophic resource partitioning. The similarity of the diversification of individuals in the process of trophic resource partitioning does not depend on the type of the compared populations, it is also evidenced by the fact that in Fig. $4 a$ and $4 b$, where the trp-vectors of monomorphic and polymorphic populations are compared, the correlations are higher than in Fig. 3d, where the trp-vectors of two monomorphic populations are compared with each other.

In conclusion, we note that the results of this study are in good agreement with the ideas of Blackith
(1968) on the preferred directions and biologically significant vectors of variability.

\section{CONCLUSIONS}

1. The ordered constructive variability of the generalized barbs of the $B$. intermedius complex is determined by two vectors common to the monomorphic populations of lakes Awasa and Langano and the polymorphic population of Lake Tana.

2. One of the identified vectors corresponds to the diversification of individuals in the process of trophic resource partitioning.

3. The role of the second vector of variability is not obvious and requires further study.

4. Main contribution to the diversification of generalized individuals in Lake Tana is made by the vector of trophic resource partitioning.

5. The contribution of the vector of trophic resource partitioning is secondary to the diversification of generalized individuals in the populations of Langano and Awasa lakes.

6. Intensity of speciation, i.e. the evolutionary potential of the populations of the three studied lakes is determined by the proportion of variability that the vector of trophic resource partitioning introduces into the total variability of generalized individuals in each studied water body.

\section{ACKNOWLEDGEMENTS}

The author is sincerely grateful to the participants of the Joint Russian-Ethiopian Biological Expedition (JERBE), who took part in the collection of the material: M.V. Mina, Yu.Yu. Dgebuadze, A.S. Golubtsov and A.A. Darkov. Sincere gratitude to M.V. Mina (Institute of Developmental Biology, Russian Academy of Sciences), who found the time to review the first version of the manuscript and made a number of valuable comments, as well as to unknown reviewers for their kind and very constructive criticism.

\section{FUNDING}

The study was carried out within the framework of the state assignments of SIEE RAS (No. 0109-2018-0076 AAAA-A18118042490059-5) and IBIW RAS (No. 121051100104-6). The material was collected with the funds of the Long-term International Project of the Russian Academy of Sciences "Joint Russian-Ethiopian Biological Expedition".

\section{COMPLIANCE WITH ETHICAL STANDARDS}

Conflict of interests. The authors declare that they have no conflicts of interest.

Statement on the welfare of animals. All applicable international, national, and/or institutional guidelines for the care and use of animals were followed. 


\section{OPEN ACCESS}

This article is licensed under a Creative Commons Attribution 4.0 International License, which permits use, sharing, adaptation, distribution and reproduction in any medium or format, as long as you give appropriate credit to the original author(s) and the source, provide a link to the Creative Commons license, and indicate if changes were made. The images or other third party material in this article are included in the article's Creative Commons license, unless indicated otherwise in a credit line to the material. If material is not included in the article's Creative Commons license and your intended use is not permitted by statutory regulation or exceeds the permitted use, you will need to obtain permission directly from the copyright holder. To view a copy of this license, visit http://creativecommons.org/licenses/by/4.0/.

\section{REFERENCES}

Andreev, V.L., Klassifikatsionnye postroeniya $v$ ekologii $i$ sistematike (Classifications in Ecology and Systematics), Moscow: Nauka, 1980.

Andreev, V.L. and Reshetnikov, Yu.S., Analysis of phenotypic variability of geographically remote populations of the same species, in Matematicheskie metody $v$ ekologii $i$ geografii (Mathematical Methods in Ecology and Geography), Vladivostok: Far Eastern Scientific Center, Academy of Sciences of the USSR,1978, pp. 98-110.

Banister, K.E., A revision of the large Barbus (Pisces, Cyprinidae) of east and central Africa: Part II, Bull. Br. Mus. Nat. Hist. Zool., 1973, vol. 26, pp. 1-148.

Blackith, R.E., Morphometrics, in Theoretical and Mathematical Biology, Watermann, T.H. and Morowitz, H.J., Eds., New York: Blaisdell, 1965, pp. 225-249.

Dgebuadze, Yu.Yu., Mina, M.V., and Mironovsky, A.N., On estimation of phenetic relationships of Altai Osmans (Oreoleuciscus, Cyprinidae) from three lakes in Mongolia by skull characters, J. Ichthyol., 2008, vol. 48, no. 4, pp. 292-300.

Golubtsov, A.S., Fish species flocks in lakes and rivers: sympatric divergence in faunistically depauperated fish communities as particular mode of evolution, in Aktual'nye problemy sovremennoi ikhtiologii (k 100-letiyu G.V. Nikol'skogo) (Current Topics of Modern Ichthyology (Dedicated to the 100th Anniversary of G.V. Nikol'skii)), Moscow: KMK, 2010, pp. 96-123.

Kaiser, H.F., The application of electronic computers to factor analysis, Educ. Psychol. Meas., 1960, vol. 20, no. 1, pp. $141-151$.

Levin, B.A., The structure of local population systems in fishes of genus Barbus, Materialy II Mizhnarodnoi naukovoi konferentsii "Bioriznomanittya ta rol' zootsnozu v prirodnikh $i$ antropogennikh ekosistemakh" (Proc. II Int. Sci. Conf. "Biological Diversity and Role of Zoocenosises in Natural and Anthropogenic Ecosystems"), Dnepropetrovsk: Dnepropetrovsk. Nats. Univ., 2003, pp. 53-55.
Levin, B.A., Casal-López, M., Simonov, E., et al., Adaptive radiation of barbs of the genus Labeobarbus (Cyprinidae) in the East African river, Freshwater Biol., 2019, vol. 64 , no. 10 , pp. $1721-1736$.

https://doi.org/10.1111/fwb.13364

Mina, M.V., Mironovsky, A.N., and Dgebuadze, Yu.Yu., Alometria et divergence entre les barbeaux du lac Tana (Ethiopie), Cah. Ethol., 1993, vol. 13, pp. 219-222.

Mina, M.V., Mironovsky, A.N., and Dgebuadze, Yu.Yu., Morphometry of barbel of Lake Tana, Ethiopia: multivariate ontogenetic channels, Folia Zool., 1996a, vol. 45, suppl. 1, pp. 109-116.

Mina, M.V., Mironovsky, A.N., and Dgebuadze, Yu.Yu., Lake Tana large barbs: phenetics, growth and diversification, J. Fish Biol., 1996b, vol. 48, pp. 383-404.

Mina, M.V., Mironovsky, A.N., Golubtsov, A.S., and Dgebuadze, Yu.Yu., 'Barbus' intermedius species flock in Lake Tana (Ethiopia). II. Morphological diversity of "large barbs" from Lake Tana and neighbouring areas: homoplasies or synapomorphies? Ital. J. Zool., 1998, vol. 65, suppl., pp. 9-14.

Mina, M.V., Mironovsky, A.N., and Dgebuadze, Yu.Yu., Polymorphism of skull proportions in large African barbs Barbus intermedius sensu Banister (Cyprinidae) from Lakes Awasa and Langano (Rift Valley, Ethiopia), J. Ichthyol., 2016, vol. 56, no. 4, pp. 498-504.

https://doi.org/10.1134/S0032945216040068

Mironovskii, A.N., Factors determining the comparability of data obtained by estimation of morphometric characters in fish, J. Ichthyol., 2006, vol. 46, no. 2, pp. 178-189.

https://doi.org/10.1134/S0032945206020056

Mironovsky, A.N., Large African barbs: vectors of diversification of individuals of the generalized form as the source of phenetic diversity of the Barbus intermedius complex in Lake Tana, Ethiopia, J. Ichthyol., 2020, vol. 60, no. 3, pp. 387-398.

https://doi.org/10.1134/S0032945220030091

Nagelkerke, L.A.J., Sibbing, F.A., van den Boogaart, J.G.M., et al., The barbs (Barbus spp.) of Lake Tana: a forgotten species flock? Environ. Biol. Fish., 1994, vol. 39, pp. 1-21. https://doi.org/10.1007/BF00004751

Rohlf, F.J., NTSYS-pc: Numerical Taxonomy and Multivariate Analysis System (Version 2.0), New York: Exeter Software, 1998.

Sibbing, F.A. and Nagelkerke, L.A.J., Resource partitioning by Lake Tana barbs predicted from fish morphometrics and prey characteristics, Rev. Fish Biol. Fish., 2001, vol. 10, no. 4, pp. 393-437.

https://doi.org/10.1023/A:1012270422092

Sibbing, F.A., Nagelkerke, L.A.J., Stet, R.J.M., and Osse, J.W.M., Speciation of endemic Lake Tana barbs (Cyprinidae, Ethiopia) driven by trophic resource partitioning; a molecular and ecomorphological approach, Aquat. Ecol., 1998, vol. 32, pp. 217-227.

https://doi.org/10.1023/A:1009920522235

Translated by D. Pavlov 